\title{
Assessing the relative risk of land based pollutants to the Great Barrier Reef
}

\author{
$\underline{\text { Jane Waterhouse }}^{1,2}$, Jon Brodie ${ }^{1}$, Jeffrey Maynard ${ }^{2,3}$ \\ ${ }^{I}$ Catchment to Reef Group, The Centre for Tropical Water and Aquatic Ecosystem Research (TropWATER), \\ James Cook University, Townsville \\ Email: jane.waterhouse@jcu.edu.au \\ ${ }^{2} \mathrm{C}_{2} \mathrm{O}$ Consulting coasts climate oceans \\ ${ }^{3}$ Laboratoire d'Excellence 'CORAIL' USR 3278 CNRS - EPHE, CRIOBE, Papetoai, Moorea, Polynesie \\ Francaise
}

\begin{abstract}
The iconic Great Barrier Reef (GBR) in Australia faces increasing pressure from human activities and has considerable ecological, cultural, social and economic values. Substantial evidence exists that links the degradation of GBR ecosystems, including reduction in coral cover, to declining water quality in the GBR. The loads of suspended sediment, nutrients and pesticides ('pollutants') discharged to the GBR from agricultural and urban development has increased greatly in the last 150 years. The pollutants disperse offshore during summer high flow events and pose a range of threats to valuable GBR ecosystems including coral reefs and seagrass meadows.
\end{abstract}

We have developed and applied a risk assessment method to guide policy makers and catchment managers on the key land-based pollutants of greatest risk to the health of the two main GBR ecosystems, coral reefs and seagrass meadows. The risk assessment method used a combination of qualitative and semi-quantitative information about the influence of individual catchments, in the 6 natural resource management (NRM) regions, on coral reefs and seagrass meadows. The method uses a Multi Criteria Analysis approach with the application of a spatial multi criteria analysis tool, Multi-Criteria Analysis Shell for Spatial Decision Support (MCAS-S) developed by ABARES (refer to http://www.daff.gov.au/abares/data/mcass) in conjunction with ArcGIS for spatial analysis.

The combined assessment of water quality variables was used to identify the areas of highest relative risk to degraded water quality in the GBR, and hence the areas where coral reefs and seagrass are most likely to be under pressure from degraded water quality. The relative risk was estimated from the areas of coral reefs and seagrass meadows exposed to a combination of defined pollutant thresholds (observed or modelled). The results indicate that the risk is greatest for coral reefs in the Fitzroy and Mackay Whitsunday regions, and for seagrass in the Burdekin and Fitzroy regions.

The combined assessment of these results with end of catchment pollutant load information allows us to draw conclusions about the overall risk of pollutants to the GBR. In summary, the greatest risk to coral reefs and seagrass meadows in terms the potential water quality impact and end -of -catchment anthropogenic loads of pollutants to the GBR is in the Wet Tropics region followed by the Fitzroy and Burdekin regions. However, it is important to reiterate that the rankings between NRM regions are relative, and do not represent absolute differences in the risk to GBR ecosystems.

In conjunction with information on pollutant generation from dominant land uses in the GBR catchments, the results are being used to inform future investment priorities for reducing pollutant runoff to the GBR under Reef Plan 3 and Reef Rescue 2. The methods are relevant for application in other management settings where combination of information from a range of sources is required and where weighting of factors may be desirable.

Keywords: Great Barrier Reef, risk assessment, pollutants, water quality 


\section{INTRODUCTION}

Exposure to land-sourced pollution has been identified as an important factor in the world-wide decline in coral reef condition (Burke et al., 2011). The Great Barrier Reef (GBR) in Australia is also subject to increasing pressure from human activities. The most recent scientific consensus from a multidisciplinary group of scientists concluded that 'key GBR ecosystems are showing declining trends in condition due to continuing poor water quality, cumulative impacts of climate change and increasing intensity of extreme events' (Brodie et al., 2013a). It is also concluded that the decline of marine water quality associated with terrestrial runoff from the adjacent catchments is a major cause of the current poor state of many of the key marine ecosystems of the GBR (see also Schaffelke et al., 2013).

The loads of suspended sediment, nutrients and pesticides ('pollutants') discharged to the GBR from agricultural and urban development has increased greatly in the last 150 years (Kroon et al., 2013). The main sources of pollutants in the catchments are nitrogen fertilisers and pesticides from intensive cropping (predominantly sugarcane) in coastal areas, and sediments derived from erosion in large areas of dryland grazing in the upper catchments (see Kroon et al., 2013). The pollutants disperse offshore during summer high flow events and pose a range of threats to valuable GBR ecosystems including coral reefs and seagrass meadows (Schaffelke et al., 2013).

The influence from land-sourced pollutants varies throughout the Great Barrier Reef World Heritage Area (GBRWHA). The degree of exposure is a function of factors such as distance from the coast, the magnitude of river discharges, the distance from river mouths, wind and ocean current directions, the varying mobility of pollutant types, and of course the different land-uses in the 6 natural resource management (NRM) regions of the GBR catchment. This differential exposure of important ecosystems such as coral reefs and seagrass meadows to land-sourced pollutants has important consequences for the prioritisation of management of agricultural pollution in the catchments.

To date the prioritisation of management responses between different pollutants, land uses industries and NRM regions in the GBR has used methods such as Multiple Criteria Analysis (MCA) (e.g. Cotsell et al., 2009; Greiner et al., 2005; Waterhouse et al., 2012). MCA is one way of approaching the assessment of complex issues, particularly where consideration of environmental, social and economic factors is required.

While these analyses have been useful for prioritisation of management response and investment under Reef Plan and Reef Rescue, more sophisticated analyses are now needed to more confidently prioritise between pollutants, across the individual catchments. Importantly, these analyses have varied in their ability to incorporate social and economic factors. This paper refers to the most current assessment of the relative risk of degraded water quality to GBR ecosystems. The assessment method is briefly described in this paper.

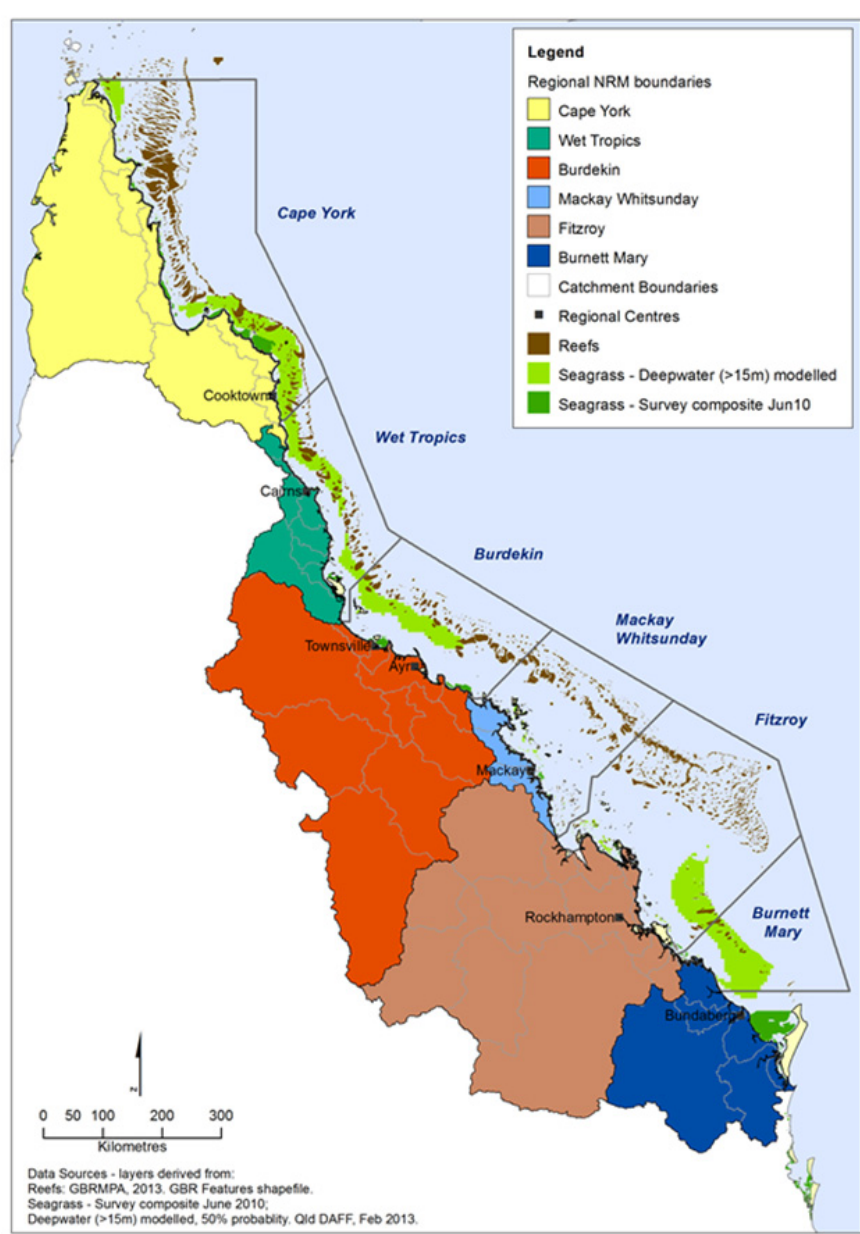

Figure 1. Map showing the assessment boundaries considered in this risk assessment. 


\section{THE RISK ASSESSMENT FRAMEWORK}

In our study we assessed the relative risk of degraded water quality to the GBR by combining information on end-of-catchment pollutant loads of sediments, nutrients and pesticides with the estimated ecological risk of water quality to coral reefs and seagrass meadows on a regional basis. The geographic boundaries of the assessment and the spatial distribution of coral reefs and seagrass meadows are shown in Figure 1. The marine boundaries used for each NRM region are those established officially by the Great Barrier Reef Marine Park Authority.

The assessment framework is shown in Figure 2. Three primary indexes were developed: 1) a Marine Risk Index that represents an estimate of ecological risk of water quality to coral reefs and seagrass; 2) a Loads Index that represents the contribution of pollutant loads from each NRM region; and 3) a crown-of-thorns starfish (COTS) Influence Index that represents the regional contribution of observed freshwater discharge to the area where primary outbreaks of COTS are known to occur. The three indexes were combined to generate a Relative Risk Index for coral reefs and seagrass meadows. This index ultimately ranks the relative risk of degraded water quality to coral reefs and seagrass in the GBR among NRM regions.

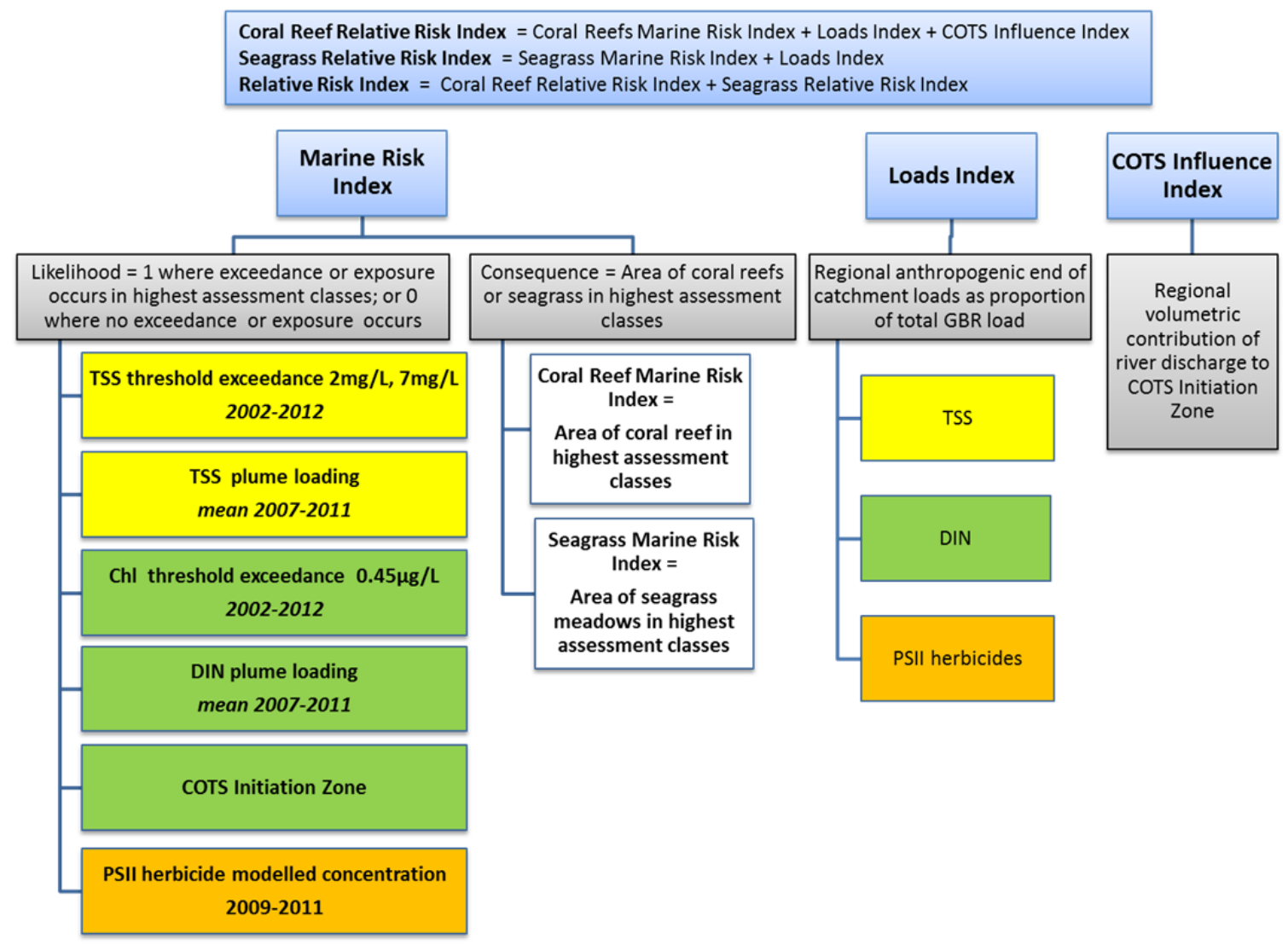

Figure 2. The risk assessment framework incorporating a Marine Risk Index, a Loads Index and a COTS Influence Index to assess the relative risk of degraded water quality to the GBR (Brodie et al., 2013b).

\section{Marine Risk Index}

To estimate ecological risk in this assessment, we selected seven water quality variables that represent the pollutants of greatest concern to ecosystems from agricultural runoff. To account for limitations in the available datasets (see Brodie et al., 2013b for further explanation), ecological risk was expressed as the area of coral reefs and seagrass meadows within a range of spatially defined assessment classes (very low to very high relative risk) for several water quality variables in each NRM region. The variables included ecologically relevant thresholds for concentrations of total suspended solids (TSS) and chlorophyll $a$ from daily remote sensing observations, and the distribution of key pollutants including TSS, dissolved inorganic nitrogen (DIN) and photosystem II-inhibiting herbicides (PSII herbicides) (see Lewis et al., 2013) in the marine environment during flood conditions (based on an assessment of flood plume frequency and predicted distribution of end-of-catchment loads). A spatial variable was included that represents the area of the GBR lagoon where primary crown-of-thorns starfish (COTS) outbreaks have been observed in northern parts of the 
GBR, approximately between Lizard Island and Cairns (Furnas et al., 2013). COTS outbreaks are an important cause of coral loss on the GBR and appear to be a response to excess nutrient runoff from certain catchments that impact this 'COTS initiation zone' (Furnas et al., 2013). The method for combining these variables is described in Section 3.

\section{Loads Index}

Modelled end-of-catchment pollutant loads, generated from the Source Catchments model framework for the Paddock to Reef Program (Waters et al., 2013), were obtained for each NRM region for key pollutants. Only the anthropogenic portions were considered as these are assumed to be the 'manageable' portion of pollutant loads. The anthropogenic load is calculated as the difference between the long term average annual load (when 2008-2009 management inputs and distributions are assumed), and the estimated pre-European load. This information was used to define a 'Loads Index'.

\section{COTS Influence Index}

In recognition of the importance of the influence of catchment discharges in driving COTS outbreaks (see Furnas et al., 2013), an index of regional contributions of river discharges to the COTS initiation zone was also included for coral reefs; the 'COTS Influence Index'.

\section{METHODS}

Given the scope of these proceedings, the focus of the methods described in this paper is on the application of modelling techniques in our assessment of the combined risk of pollutants on GBR ecosystems (the Marine Risk Index). A full description and justification of the methods, including the detail of the technique for combining the three indexes, is found in Brodie et al. (2013b).

For each of the variables shown in Figure 2 a classified spatial data layer was prepared in ArcGIS. The classifications were customised based on the expert opinions of the project team. ArcGIS was the primary tool used for spatial analysis in this study; however, the Multi-Criteria Analysis Shell for Spatial Decision Support (MCAS-S) was also used for some aspects of this assessment to align with the Australian Government's associated Reef Rescue 2 Investment Prioritisation process (see Barson et al., 2013). MCAS-S was used to test and ultimately select approaches for combining and weighting the datasets. After testing several approaches to weighting the variables, it was agreed to weight each spatial layer equally. The data layers were then combined using the Composite tool in MCAS-S and the values of each coincident pixel were summed, normalised and classified into five even break classes ranging from Very Low to Very High. An example of the process applied in MCAS-S is shown in Figure 3.

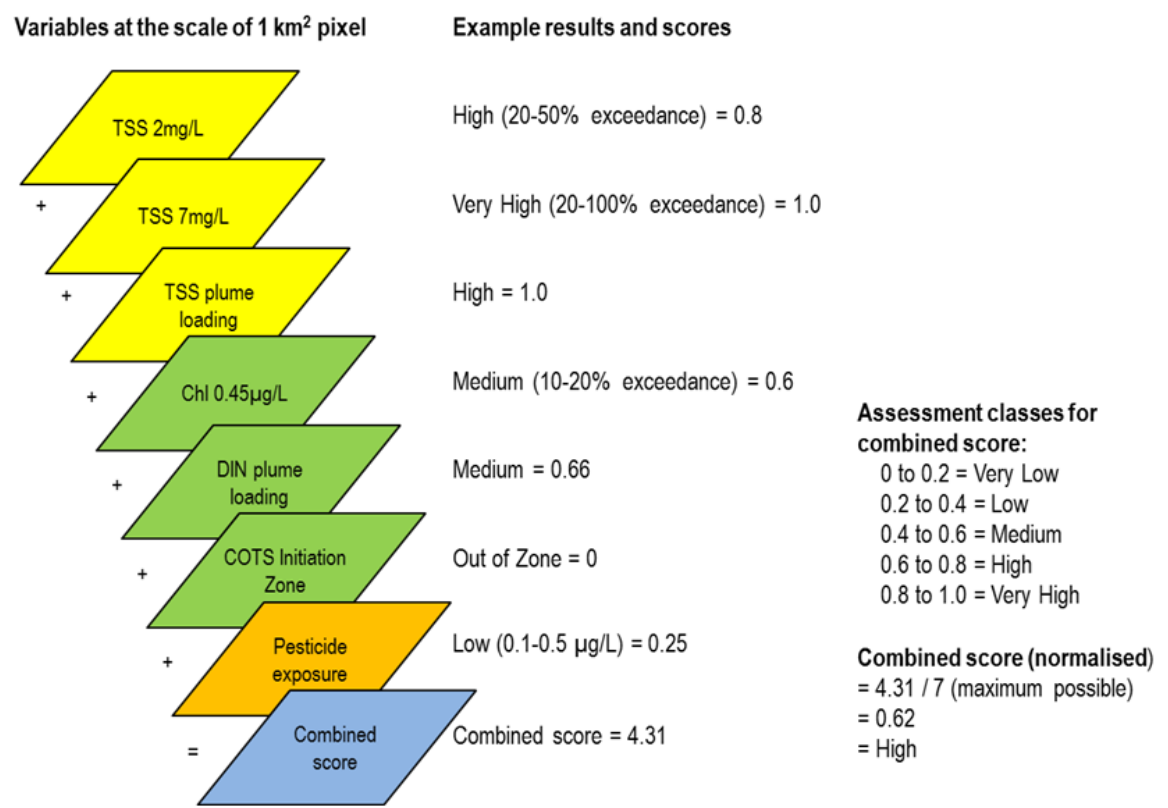

Figure 3. Example of the results in one cell in MCAS-S. The result for coincident cells from each layer is summed to give a combined score, normalised and classified into five assessment classes (Very Low to Very High). In this example the combined score gives the cell a score within the High assessment class in terms of relative risk of degraded water quality. Source: Brodie et al. (2013b). 
The area of coral reefs and seagrass meadows in each of the five assessment classes of the combined layer was calculated for comparison between regions. The Marine Risk Index was defined by summing the areas of coral reefs and seagrass meadows in the highest assessment classes of the combined layer, and anchoring those results to the maximum area among regions. This enabled an assessment of the relative differences between regions in terms of combined water quality risk for coral reefs and seagrass meadows. The final output is a Coral Reef Marine Risk Index and a Seagrass Marine Risk Index. These results were summed with ranked scores of the Loads Index and COTS Influence Index to determine the overall relative risk of degraded water quality to coral reef and seagrass ecosystems in the GBR. These aspects of the method are described in further detail in Brodie et al. (2013b).

\section{RESULTS}

The assessment of the combined variables identified the areas of highest relative risk to degraded water quality in the GBR and hence the areas where coral reefs and seagrass are most likely to be under pressure from degraded water quality. The results indicate that the risk is greatest for coral reefs in the Fitzroy and Mackay Whitsunday regions, and for seagrass in the Burdekin and Fitzroy regions. In most cases, the proportion of the habitat area in each region that is in the highest risk areas are less than $10 \%$, except in the case of seagrass meadows in the Mackay Whitsunday region where 37\% of the area of seagrass in the region is affected. This may have significant implications at a regional scale and warrants further consideration.

These high risk areas include highly valued tourism and recreation sites of the GBR. Examples include Fitzroy Island and Hinchinbrook Island (Wet Tropics region), Magnetic Island (Burdekin region), many of the islands in the Whitsunday Group (Mackay Whitsunday region) and the Keppel Island group (Fitzroy region). Inshore seagrass meadows are also of critical importance to dugong and green turtle populations in the GBR and many of the highest risk areas overlap with dugong protection areas (DPAs), which are assigned because of the large populations of dugongs feeding in the associated seagrass meadows.

The combined assessment of these results with the Loads Index and COTS Influence Index allow us to draw conclusions about the overall risk of pollutants to the GBR. In summary, the greatest risk to each habitat in terms of the potential water quality impact from all of the assessment variables in the GBR and end -of catchment anthropogenic loads of DIN, TSS and PSII herbicides is:

- Coral reefs: Wet Tropics region, followed by the Fitzroy region. The rank of the remaining regions is the Mackay Whitsunday, Burdekin, Cape York and Burnett Mary region.

- Seagrass meadows: Burdekin region, followed by the Wet Tropics. The rank of the remaining regions is the Fitzroy, Mackay Whitsunday, Burnett Mary and Cape York region.

- Coral reefs and seagrass meadows combined: Wet Tropics region, followed by the Fitzroy and Burdekin. The rank of the remaining regions is Mackay Whitsunday, Burnett Mary and Cape York region.

While the assessment has generated the most comprehensive assessment of the relative risk of degraded water quality to GBR ecosystems undertaken to date, it is important to reiterate that the rankings between NRM regions are relative, and do not represent absolute differences in the risk to GBR ecosystems. We recommend that this information can be useful in guiding investment priorities but should not be used in isolation from other knowledge related to regionally specific priorities supported by additional evidence, socio economic influences and limitations to the assessment that may have led to uncertainties in the results.

A number of limitations in the data and methodology became apparent during the course of the analysis. Some of the most important of these were:

1. Data used in the analysis for inshore chlorophyll $a$ and TSS from remote sensing is based on a quite limited set of valid observations due to cloud, sun glint and other factors interfering with interpretation of the satellite data.

2. The assessed risk posed by pesticides is an underestimate due to the limited number of pesticides considered (PSII herbicides only), potential additive and synergistic effects of pesticides with other stressors (e.g. temperature) were not considered and only acute stress was used as no time dependent factors (which could produce dosage) were included.

3. Potential risk has not been assessed equally across all NRM regions due to geographical boundaries of the assessment. In particular, in the Burnett Mary region a large part of the marine area which may be 
influenced by runoff from GBR catchments are outside of the GBRWHA and therefore were not included in the assessment. These areas contain high ecological value seagrass and coral reef systems, and dugong and turtle populations.

4. Only coral reefs and seagrass meadows were analysed (but see limitation 3) while ecosystems such as mangroves, soft-bottomed communities and fisheries resources were not.

5. Surface exposure and loading factors were assessed from a data set which included data from 2007 2011. This was a particularly wet period in the GBR with major river flows and may not be fully representative of the long-term values.

6. Only a limited range of pollutants were assessed in the model. Phosphorus was not explicitly considered and other herbicides, toxic metals, microplastics, oil and pharmaceuticals not included.

The limitations of the assessment are described in more detail in Brodie et al., (2013b).

\section{CONCLUSIONS}

The methodology used in this assessment has produced results that can be used to identify regional differences in the relative risk of degraded water quality to GBR ecosystems. Coupled with modelled land use specific pollutant load estimates and erosion sources using the Source Catchments model (see Waters et al., 2013), and knowledge of social and economic factors influencing management action at a regional scale, the results can be used to generate the management priorities for improving water quality in the GBR. A preliminary assessment of management prioritisation for the NRM regions has recently been undertaken using this information (see Brodie et al., 2013b and Barson et al., 2013) for Reef Plan 3, incorporating Reef Rescue 2. However, a more detailed regional analysis is required to inform on-ground investment priorities. In particular, further investigation is required to establish the most suitable social and economic indicators to be used in this type of assessment in the future.

While more effective risk assessment methodologies will be developed in the future, such as those that incorporate more complex marine models being developed through eReefs (Chen et al. 2011), these tools may not be available for use for several years. In the mean time less complex methods as used in the current assessment will be required to continue to be used for management prioritisation of water quality issues in the GBR. The methods are relevant for application in other management settings where combination of information from a range of sources is required and where weighting of factors may be desirable.

\section{ACKNOWLEDGMENTS}

The authors would like to thank the Queensland Department of Environment and Heritage Protection for the project funding and the contribution from Lucy Randall (ABARES) for the MCAS-S analysis.

\section{REFERENCES}

Barson, M., Randall, L., and Gale. K.R. (2013). Using multi-criteria analysis models for the prioritisation of investment in the Great Barrier Reef. Extended Abstract in: MODSIM2013, 20th International Congress on Modelling and Simulation. Modelling and Simulation Society of Australia and New Zealand, December 2013, this issue.

Brodie, J., Waterhouse, J., Schaffelke, B., Johnson, J.E., Kroon, F., Thorburn, P., Rolfe, J., Lewis, S., Warne, M.St.J., Fabricius, K., McKenzie, L., and Devlin, M. (2013a). Reef Water Quality Scientific Consensus Statement 2013. Department of the Premier and Cabinet, Queensland Government, Brisbane.

Brodie, J., Waterhouse, J., Maynard, J., Bennett, J., Furnas, M., Devlin, M., Lewis, S., Collier, C., Schaffelke, B., Fabricius, K., Petus, C., da Silva, E., Zeh, D., Randall, L., Brando, V., McKenzie, L., O’Brien, D., Smith, R., Warne, M.St.J., Brinkman, R., Tonin, H., Bainbridge, Z., Bartley, R., Negri, A., Turner, R.D.R., Davis, A., Bentley, C., Mueller, J., Alvarez-Romero, J.G., Henry, N., Waters, D., Yorkston, H., and Tracey, D. (2013b). Assessment of the relative risk of water quality to ecosystems of the Great Barrier Reef. A report to the Department of the Environment and Heritage Protection, Queensland Government, Brisbane. TropWATER Report 13/28, Townsville, Australia.

Burke, L., Reytar, K., Spalding, M., and Perry, A. (2011). Reefs at risk revisited. World Resources Institute, Washington, DC, p. 114. Available at www.wri.org.

Chen, Y., Minchin, S.A., Seaton, S., Joehnk, K.D., Robson, B.J., and Bai, Q. (2011). eReefs - a new perspective on the Great Barrier Reef. Proceedings of the 19th International Congress on Modelling and Simulation, Perth, Australia, 12-16 December 2011. www.mssanz.org.au/modsim2011/C4/chen.pdf 
Cotsell, P., Gale, K., Hajkowicz, S., Lesslie, R., Marshall, N., and Randall, L. (2009). Use of a multiple criteria analysis (MCA) process to inform Reef Rescue regional allocations. In: Proceedings of the 2009 Marine and Tropical Sciences Research Facility Annual Conference 28-30 April 2009 Rydges Southbank Hotel, Townsville. Compiled by Shannon Hogan and Suzanne Long Reef and Rainforest Research Centre Limited.<http://www.rrrc.org.au/publications/downloads/Theme-5-RRRC-2009-Annual-ConferenceProceedings.pdf $>$.

Furnas, M., Brinkman, R., Fabricius, K., Tonin, H., and Schaffelke, B. (2013). Chapter 1: Linkages between river runoff, phytoplankton blooms and primary outbreaks of crown-of-thorns starfish in the Northern GBR. In: Assessment of the relative risk of water quality to ecosystems of the Great Barrier Reef: Supporting Studies. A report to the Department of the Environment and Heritage Protection, Queensland Government, Brisbane. TropWATER Report 13/30, Townsville, Australia.

Greiner, R., Herr, A., Brodie, J., and Haynes, D. (2005). A multi-criteria approach to Great Barrier Reef catchment (Queensland, Australia) diffuse-source pollution problem. Marine Pollution Bulletin 51, 128137.

Kroon, F., Turner, R., Smith, R., Warne, M., Hunter, H., Bartley, R., Wilkinson, S., Lewis, S., Waters, D., and Carroll, C. (2013). Sources of sediment, nutrients, pesticides and other pollutants in the Great Barrier Reef catchment. Synthesis of evidence to support the Reef Water Quality Scientific Consensus Statement 2013. Department of the Premier and Cabinet, Queensland Government, Brisbane.

Lesslie, R.G., Hill, M.J., Hill, P., Cresswell, H.P., and Dawson, S. (2008). The Application of a Simple Spatial Multi-Criteria Analysis Shell to Natural Resource Management Decision Making. In Landscape Analysis and Visualisation: Spatial Models for Natural Resource Management and Planning, (Eds. Pettit, C, Cartwright, W, Bishop, I, Lowell, K, Pullar, D \& Duncan, D), Springer, Berlin, pp 73-96.

Lewis, S., Smith, R., O’Brien, D., Warne, M.St.J., Negri, A., Petus, C., da Silva, E., Zeh, D. Turner, R.D.R., Davis, A., Mueller, J., and Brodie, J. (2013). Chapter 4: Assessing the risk of additive pesticide exposure in Great Barrier Reef ecosystems. In: Assessment of the relative risk of water quality to ecosystems of the Great Barrier Reef: Supporting Studies. A report to the Department of the Environment and Heritage Protection, Queensland Government, Brisbane. TropWATER Report 13/30, Townsville, Australia.

Schaffelke, B., Anthony, K., Blake, J., Brodie, J., Collier, C., Devlin, M., Fabricius, K., Martin, K., McKenzie, L., Negri, A., Ronan, M., Thompson, A., and Warne, M.St.J. (2013). Marine and coastal ecosystem impacts. Synthesis of evidence to support the Reef Water Quality Scientific Consensus Statement 2013. Department of the Premier and Cabinet, Queensland Government, Brisbane.

Thorburn, P., Rolfe, J., Wilkinson, S., Silburn, M., Blake, J., Gongora, M., Windle, J., VanderGragt, M., Wegschield, C., Ronan, M., and Carroll, C. (2013). The water quality and economic benefits of agricultural management practices. Synthesis of evidence to support the Reef Water Quality Scientific Consensus Statement 2013. Department of the Premier and Cabinet, Queensland Government, Brisbane.

Waterhouse, J., Brodie, J., Lewis, S., and Mitchell, A. (2012). Quantifying the sources of pollutants to the Great Barrier Reef. Marine Pollution Bulletin 65, 394- 406.

Waters, D., Carroll, C., Ellis, R., McCloskey, G., Hateley, L., Packett, B., Dougall, C. and Fentie, B. (2013). Catchment modelling scenarios to inform GBR water quality targets. In: MODSIM2013, 20th International Congress on Modelling and Simulation. Modelling and Simulation Society of Australia and New Zealand, December 2013, this issue. 